\title{
Gangrena de Fournier: Da Região Perianal à Parede Abdominal
}

\section{Fournier's Gangrene: From the Perianal Region to the Abdominal Wall}

Nuno Oliveira ${ }^{1}$, Pedro Carvalho' ${ }^{1}$, Hugo Queimado ${ }^{1}$, Francisco Rodrigues ${ }^{1}$

PALAVRAS-CHAVE: Desbridamento; Gangrena de Fournier

KEYWORDS: Debridement; Fournier Gangrene

Mulher, de 55 anos, com antecedentes de obesidade mórbida, dislipidemia e diabetes mellitus não insulino-tratada, recorreu ao serviço de urgência por quadro de queixas álgicas e sinais inflamatórios na região perianal direita com uma semana de evolução.

Ao exame objetivo identificava-se tumefação e rubor na região perianal direita, compatível com abcesso perianal. Apirética, hipotensa (93/59 mmHg) e taquicárdica (105 bpm).

Por dor na palpação abdominal e rubor nos quadrantes inferiores da parede abdominal decidiu-se realizar tomografia computorizada abdomino-pélvica de modo a avaliar a extensão do processo inflamatório.

O estudo analítico revelou PCR de 40 mg/dL e lesão renal aguda (creatinina 2,8 mg/dL e ureia 150 mg/dL). A tomografia computorizada revelou "extenso enfisema em topografia paramediana direita na cavidade pélvica e gordura pré-sagrada, com extensão ao longo dos vasos ilíacos, à região inguinal homolateral e à parede abdominal no quadrante inferior direito (...) compatível com gangrena de Fournier. Densificação da gordura subcutânea na parede abdominal anterior infra-umbilical. (...)".

Foi submetida a drenagem de extenso abcesso perianal e desbridamento de tecido desvitalizado desde a região perianal direita (Fig. 1) até às regiões suprapúbica, fossa ilíaca esquerda e flanco esquerdo (Fig. 2). Iniciou antibioterapia empírica e tratamento em câmara hiperbárica. Foram realizados desbridamentos seriados e colostomia terminal derivativa. Apresentou evolução lenta, mas globalmente favorável. Contudo, mesmo sob terapêutica com inibidores da bomba de protões, faleceu ao $50^{\circ}$ dia de internamento na sequência de laparotomia urgente por perfuração de úlcera gástrica. 


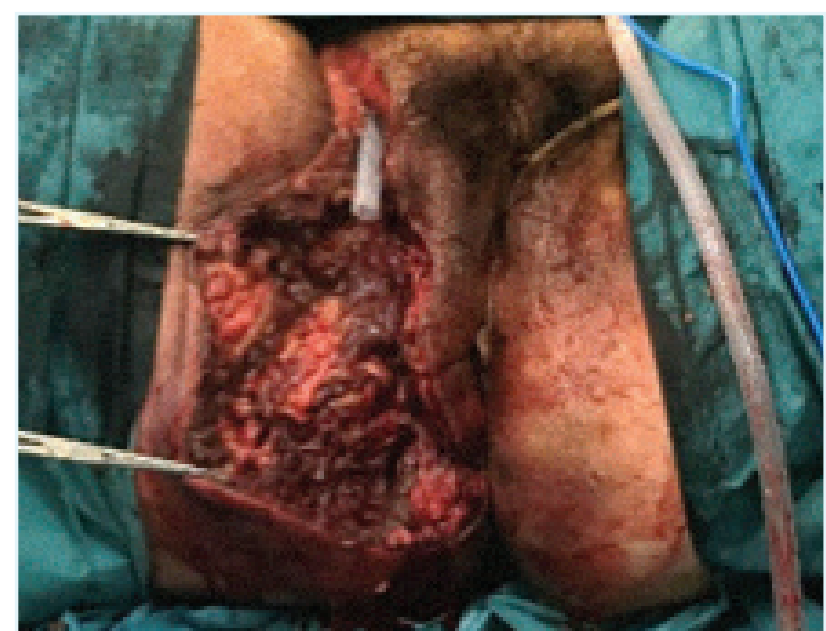

FIGURA 1. Gangrena de Fournier após drenagem e desbridamento de tecido desvitalizado: região perianal.

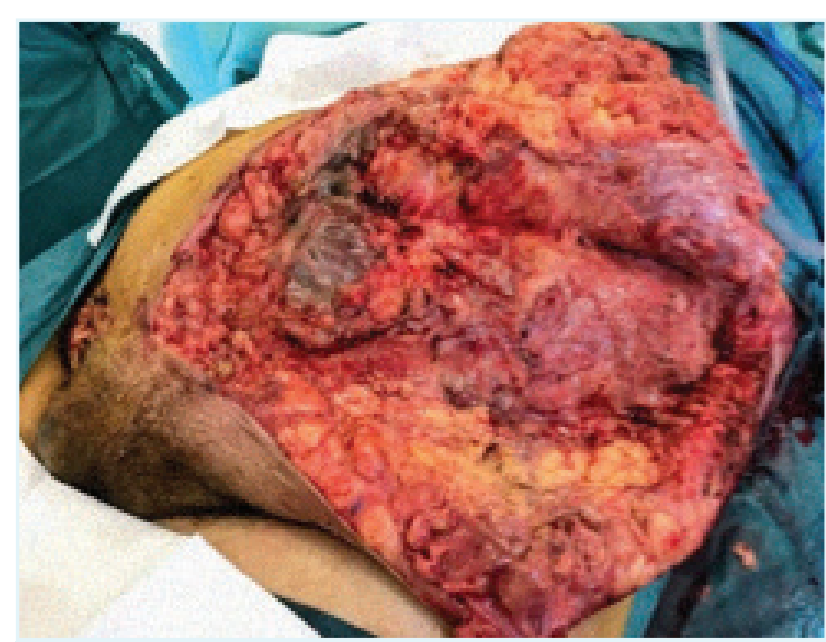

FIGURA 2. Gangrena de Fournier após drenagem e desbridamento de tecido desvitalizado: parede abdominal esquerda

A gangrena de Fournier enquadra-se num conjunto de patologias que se manifestam por infeção e necrose de tecidos moles em profundidade. O tratamento cirúrgico e médico não deve ser protelado uma vez que a morbilidade e mortalidade associadas são grandes. ${ }^{1}$ Além de drenagem e desbridamento de tecidos as sessões em câmara hiperbárica são uma mais-valia para a resolução destas situações. ${ }^{2,3}$

CONFLITOS DE INTERESSE: Os autores declaram não ter qualquer conflito de interesse na realização do presente trabalho.

FONTES DE FINANCIAMENTO: Não houve qualquer fonte de financiamento na realização do presente trabalho.

CONFIDENCIALIDADE DOS DADOS: Os autores declaram ter seguido os protocolos da sua instituição acerca da publicação dos dados de doentes.

PROTEÇÃO DE PESSOAS E ANIMAIS: Os autores declaram que os procedimentos seguidos na elaboração do presente trabalho estão em conformidade com as normas das comissões de investigação clínica e de ética, bem como da declaração de Helsínquia e da Associação Médica Mundial.

\section{CONSENTIMENTO DO DOENTE: Obtido.}

CONFLICTS OF INTEREST: The authors declare that they have no conflicts of interest.

FINANCIAL SUPPORT: This work has not received any contribution, grant or scholarship.

CONFIDENTIALITY OF DATA: The authors declare that they have followed the protocols of their work center on the publication of data from patients.

PROTECTION OF HUMAN AND ANIMAL SUBJECTS: The authors declare that the procedures followed were in accordance with the regulations of the relevant clinical research ethics committee and with those of the Code of Ethics of the World Medical Association (Declaration of Helsinki).

PATIENT CONSENT: Obtained.

\section{REFERÊNCIAS}

1. Voelzke BB, Hagedorn JC. Presentation and diagnosis of Fournier gangrene. Urology. 2018;114:8-13.

2. Korhonen K, Hirn M, Niinikoski J. Hyperbaric oxygen in the treatment of Fournier's gangrene. Eur J Surg. 1998;164:2515.

3. Gandhi J, Seyam O, Smith NL, Joshi G, Vatsia S, Khan SA. Clinical utility of hyperbaric oxygen therapy in genitourinary medicine. Med Gas Res. 2018;8:29-33. 